coupling start intervals (PA start) and PA peak intervals (PA peak) by TDE. Isolated Langendorff perfused rabbit hearts were used to evaluate interatrial conduction time (IACT) and vulnerability to AF which examined by burst pacing.

Results Compared with controls, left atrial diameter (LAD), interventricular septum thickness (IVST), atrial PAs measured at the left atrial (LA) lateral wall (latPAstart) and right atrial (RA) wall (raPAstart) were greater in diabetic rabbits (LAD $6.8 \pm 0.6$ vs $8.3 \pm 0.6 \mathrm{~mm}, \mathrm{p}<0.01$; IVST $1.9 \pm 0.2$ vs $3.0 \pm 0.5 \mathrm{~mm}$ $\mathrm{p}<0.01$; latPAstart $40.5 \pm 12.9$ vs $60.4 \pm 20.4 \mathrm{~ms} \mathrm{p}<0.05$; raPAstart $59.8 \pm 20.1$ vs $83.0 \pm 11.0 \mathrm{~ms} p<0.05)$. IACT in diabetic rabbits was prolonged than controls $(37.6 \pm 8.9$ vs $27.7 \pm 2.1 \mathrm{~ms} \mathrm{p}<0.01)$. Inducibility of AF in diabetic group was significant higher than controls (6/8 vs 1/8, $\mathrm{p}<0.05)$. Correlation analysis showed that inter-atrial septum (IAS) PAstart, LA post wall PAstart and LA post wall PA peak were correlated with IACT $(r=0.634,0.562$, 0.629 , respectively, $\mathrm{p}<0.05$ ).

Conclusion Atrial electromechanical function is impaired in diabetic rabbits, which may relate to interatrial electrical conduction delay and development of AF.

[gw22-e0275]

\section{ASSESSMENT OF ATRIAL ELECTROMECHANICAL FUNCTION BY TISSUE DOPPLER ECHOCARDIOGRAPHY AND ATRIAL FIBRILLATION PROMOTION IN ALLOXAN-INDUCED DIABETIC RABBITS: AN EXPERIMENTAL STUDY}

Fu Huaying, Liu Changle, Li Jian, Zhou Changyu, Liu Tong, Li Guangping Department of Cardiology, Tianjin Institute of Cardiology, Second Hospital of Tianjin Medical University, Tianjin, People's Republic of China

10.1136/heartjnl-2011-300867.703

Purpose Diabetes mellitus is an independent risk factor for atrial fibrillation (AF). However, the underlying mechanisms are still not clearly elucidated. The aim of this study was to evaluate atrial electromechanical delay by tissue Doppler echocardiography (DTE), atrial electrophysiological changes and AF promotion in alloxan-induced diabetic rabbits.

Methods In eight alloxan-induced diabetic rabbits and eight healthy controls, the authors measured atrial electromechanical 